\title{
Simple Macroeconomic Policies and Welfare: A Quantitative Assessment*
}

\author{
Eurilton Araújo ${ }^{\dagger}$, Alexandre B. Cunha ${ }^{\ddagger}$
}

\author{
Contents: 1. Introduction; 2. The Economy; 3. Competitive Equilibrium; \\ 4. Parameterization; 5. Policy Analysis; 6. Concluding Remarks; A. Appendix. \\ Keywords: Optimal Policy, Business Cycles, Welfare. \\ JEL Code: $\quad$ E32, E61.
}

We quantitatively compare three macroeconomic policies in a cashcredit goods framework. The policies are: the optimal one; another one that fully smoothes out oscillations in output; and a simple one that prescribes constant values for tax and monetary growth rates. As often found in the related literature, the welfare gains or losses from changing from a given policy to another are small. We also show that the simple policy dominates the one that leads to constant output.

Desenvolve-se neste artigo uma comparação quantitativa, em um modelo do tipo "cash-credit goods", de três políticas macroeconômicas: a ótima, uma que leva a completa suavização das oscilações do produto e uma extremamente simples que prescreve valores constantes para as alíquotas de impostos e a taxa de crescimento da oferta de moeda. Em consonância com os resultados encontrados na literatura, os ganhos ou as perdas de se mudar de uma política para outra são modestos. Mostra-se ainda que a política simples domina, sob o ponto de vista de bem-estar, aquela que leva a um produto constante.

\footnotetext{
*The authors acknowledge financial support from the Brazilian Council of Science and Technology (CNPq) and the helpful comments of an anonymous referee. The views expressed in this paper are those of the authors and should not be interpreted as representing the positions of the Central Bank of Brazil.

${ }^{\dagger}$ Central Bank of Brazil and Fucape Business School. E-mail: eurilton@gmail.com

${ }^{\ddagger}$ Federal University of Rio de Janeiro. E-mail: research@alexbcunha.com
} 


\section{INTRODUCTION}

In this paper we study the welfare implications and other features of some macroeconomic policies in a standard cash-credit goods model. As in Chari et al. (1994, 1995), the optimal policy (i.e., the one that yields the highest utility in the competitive equilibrium set) induces an outcome in which output and other macro variables are not constant. So, fully smoothing out the business cycle is not a desirable policy.

We found there is a simple policy that yields higher utility than the one that fully smoothes GDP. Keeping the tax rate on labor income and the growth rate of the money supply constant over time is preferable to an active fiscal policy that induces the output to be constant.

We performed the standard real business cycle approach of evaluating the first and second moments of the time series generated by the model. We found that the stabilization of GDP involves a decrease in the average output and an increase in the volatility of other real variables, when compared to the outcome induced by an optimal policy.

Besides evaluating the first and second moments of the time series generated by different policy experiments, we also analyzed them in the frequency domain. We computed spectral densities for consumption, GDP and inflation. The shapes of spectral density functions across equilibria were very similar, though there were changes in scale, implying differences in volatility levels. We verified that the optimal macroeconomic policy delivered a relatively smooth consumption path without imposing the strong requirement that all output volatility has to be eliminated. In addition, the optimal macroeconomic policy displayed a low degree of comovement between consumption and GDP.

The conventional wisdom that fiscal and monetary policies should be targeted at stabilizing output and employment can be traced back at least to Keynes (1936). Indeed, still today there is a large literature aimed at quantifying the welfare cost of business cycle fluctuations. That line of research builds on Lucas (1987), who quantified the welfare gain of a hypothetical household if its consumption was kept constant at its average level instead of displaying the volatility observed in the actual U.S. data. He concluded that they were smaller than $1 \%$ of the GDP.

Lucas (1987) placed some qualifications on his result. According to him "...there is no reason to think that eliminating all consumption variability is either a feasible or desirable objective of policy...". The same argument is presented with more emphasis in Lucas (2003). Anyway, his exercise motivated several other papers that tried to quantify, in different models, the cost of business cycles. Krusell and Smith (1999), Otrok (2001), Galí et al. (2007), and Guillén et al. (2014) are typical examples of papers discussing the issue.

We believe the mentioned conventional wisdom does not take into consideration several results brought forth by the DSGE (dynamic stochastic general equilibrium) approach to macroeconomics. We elaborate on this matter on the next four paragraphs.

Kydland and Prescott (1982) simulated the competitive equilibrium behavior of consumption, output, investment and other variables of a stochastic economy that was slightly more sophisticated than the neoclassical growth model. The sources of uncertainty were shocks on the total productivity factor. Despite of the fact that their economy was extremely simple, the first and second moments and the comovements of the simulated series were quantitatively consistent with their counterparts of the actual U.S. economy. That seminal paper was the starting point of the real business cycle literature.

The assumptions of both the First and Second Welfare Theorems hold in Kydland and Prescott's economy. Furthermore, the competitive equilibrium they compute is unique. Therefore, the corresponding competitive equilibrium allocation is the unique Pareto efficient allocation. Since that unique competitive equilibrium mimics the business cycle behavior of the U.S. economy, the corollary is that the volatility observed in macroeconomic variables, such as GDP, investment and unemployment rate, are optimal responses to shocks that hit the economy.

There was no government in Kydland and Prescott's economy. Thus, their findings did not suffice to establish that cyclical oscillations would be a feature of an efficient outcome in models containing 
features such as distorting taxation, government consumption, and money. In other words, it could happen that introducing a government in Kydland and Prescott's world would lead to the conclusion that the government should actively pursue counter-cyclical policies. However, as we discuss below, that possibility did not happen.

Chari et al. (1994) studied the problem of selecting optimal tax rates in a real business cycle model. Among some other findings, they concluded that if the government selects policies in an efficient fashion, then the economy will still face business cycle fluctuations. In a related paper (Chari et al., 1995), they studied the same problem in a monetary economy. Again, business cycles constitute a feature of the efficient outcome.

All that being said, before we started our quantitative exercises we knew that a policy designed to keep the GDP constant would be dominated, under the welfare criterion, by at least one policy (the optimal one) that would not fully smooth out oscillations in output. What came as a surprise to us is that the simple policy of constant rates for both taxation and money growth dominated the policy that eliminated output fluctuations.

There is an intuitive explanation for our findings. The results of Chari et al. (1994) establish that the optimal policy prescribes a constant (and equal to zero, the well-known Friedman Rule) nominal interest rate and relatively stable tax rates on labor income. If we require the government to adjust these policy instruments to attain constant output, then they will oscillate more than in our simple policy. As a consequence, consumption and labor will be more volatile. In other words, there is a tradeoff between the volatility of output against the volatilities of consumption and labor. For this reason, pursuing constant output is not a sound policy goal.

This paper is organized as follows. Section 2 describes our model economy. Section 3 discusses the definition and the characterization of the competitive equilibrium set. Section 4 describes the parameterization of the model economy. We carry out policy exercises and evaluate their statistical and welfare implications in Section 5. We present our concluding remarks in Section 6.

\section{THE ECONOMY}

Our economy is identical to the monetary model studied in Chari et al. (1995). There exists a country populated by a single infinitely lived household and a government. The household is composed by a shopper and a worker, who is endowed with $L$ units of time.

The economy produces a single good, which is consumed by the household $(c)$ and by the government $(g)$. Technology is described by $0 \leq y \leq \theta l$, where $y$ is the output of that good and $l$ is the amount of time allocated to work.

Transactions take place in this economy in a particular way. At the first stage of each date $t$ spot markets for goods and labor services operate. At the second stage, security and currency markets operate. ${ }^{1}$

A currency $M$ circulates in this economy. A particular type of security is traded: a claim $B$, with maturity of one period, to one unit of $M$.

Shoppers face a cash-in-advance constraint. A fraction $\left(c_{1}\right)$ of the purchases of the consumption good must be paid cash. Except for the purchases of that good, all other transactions are settled during the security and currency trading session. Therefore, the difference $c-c_{1}$, denoted by $c_{2}$, does not need to be paid in cash.

Let $s_{t}$ denote the vector $\left(\theta_{t}, g_{t}\right)$. The sequence $\left\{s_{t}\right\}_{t=0}^{\infty}$ is a Markov process. Its state space is $S=\Theta \times G$, where $\Theta=\left\{\theta_{L}, \theta_{H}\right\}, G=\left\{g_{L}, g_{H}\right\}, \theta_{L}<\theta_{H}$ and $g_{L}<g_{H}$. The random variables $\theta_{t}$ and $g_{t}$ are independent. The transition probabilities are $\mu\left(g_{t+1}=g_{t}\right)=\mu_{g}$ and $\mu\left(\theta_{t+1}=\theta_{t}\right)=\mu_{\theta}$. For a

\footnotetext{
${ }^{1}$ In this world unexpected inflation does not act as a lump sum tax. Therefore, the problem of selecting an optimal policy will have a well defined solution even if the government has some outstanding debt at date zero. See Nicolini (1998), specially Section 3, for further details.
} 
given $s^{t}$ in $S^{t}, \mu\left(s^{t}\right)$ denotes the probability that the first $t$ realizations of the process will be equal to $s^{t}$. The realization of $s_{t}$ is known at the beginning of date $t$.

Each good is produced by a single competitive firm. Let $l\left(s^{t}\right)$ denote the amount of labor supplied by each household at date $t$ if the history $s^{t}$ occurs. Other variables indexed by $s^{t}$ have analogous meanings. Feasibility requires

$$
c_{1}\left(s^{t}\right)+c_{2}\left(s^{t}\right)+g_{t}=\theta_{t} l\left(s^{t}\right) .
$$

The government finances the sequence $\left\{g_{t}\right\}_{t=0}^{\infty}$ by issuing and withdrawing $M$; by issuing and redeeming $B$; and taxing labor income at rate $\tau\left(s^{t}\right)$. The government's budget constraint is

$$
p\left(s^{t}\right) g_{t}+B\left(s^{t-1}\right)+M\left(s^{t-1}\right)=\tau\left(s^{t}\right) w\left(s^{t}\right) l\left(s^{t}\right)+q\left(s^{t}\right) B\left(s^{t}\right)+M\left(s^{t}\right),
$$

where $p\left(s^{t}\right), w\left(s^{t}\right)$ and $q\left(s^{t}\right)$ are the respective date $t$ monetary prices of the consumption good, labor services and the security; and $M\left(s^{t}\right)$ and $B\left(s^{t}\right)$ are the amount of domestic currency and public debt held by households at the end of date $t$. All those variables are conditional on the history of events. A negative value for $B\left(s^{t}\right)$ means that the government is lending to domestic residents. Initial public debt $\bar{B}$ and nominal balances $\bar{M}$ satisfy $\bar{B}=0$ and $\bar{M}>0$.

The function $u: \mathbb{R}_{+}^{2} \times[0, L] \rightarrow \mathbb{R} \cup\{-\infty\}$,

$$
u\left(c_{1}, c_{2}, L-l\right)=\frac{\left\{\left[(1-\nu) c_{1}^{\rho}+\nu c_{2}^{\rho}\right]^{\frac{1-\gamma}{\rho}}(L-l)^{\gamma}\right\}^{1-\sigma}-1}{1-\sigma},
$$

is the typical household period utility function. As usual, $\gamma$ is positive, $\nu \in(0,1), \rho<1$, and $\sigma \geq 0$. Intertemporal preferences are described by

$$
\sum_{t=0}^{\infty} \sum_{s^{t} \in S^{t}} \beta^{t} \mu\left(s^{t}\right) u\left(c_{1}\left(s^{t}\right), c_{2}\left(s^{t}\right), L-l\left(s^{t}\right)\right),
$$

where $\beta \in(0,1)$. The date $t$ budget constraint of the household is

$$
\begin{gathered}
p\left(s^{t}\right)\left[c_{1}\left(s^{t}\right)+c_{2}\left(s^{t}\right)\right]+q\left(s^{t}\right) B\left(s^{t}\right)+M\left(s^{t}\right) \leq \\
{\left[1-\tau\left(s^{t}\right)\right] w\left(s^{t}\right) l\left(s^{t}\right)+B\left(s^{t-1}\right)+M\left(s^{t-1}\right) .}
\end{gathered}
$$

The constraint $\left|B\left(s^{t}\right) / p\left(s^{t}\right)\right| \leq A<\infty$ prevents Ponzi games. The household also faces the cash-inadvance constraint

$$
p\left(s^{t}\right) c_{1}\left(s^{t}\right) \leq M\left(s^{t-1}\right) .
$$

The household selects an object $\left\{\left[c_{1}\left(s^{t}\right), c_{2}\left(s^{t}\right), l\left(s^{t}\right), M\left(s^{t}\right), B\left(s^{t}\right)\right]_{s^{t} \in S^{t}}\right\}_{t=0}^{\infty}$ to maximize (4) subject to the constraints (5), (6), and $l\left(s^{t}\right) \leq 1$. Except for $B\left(s^{t}\right)$, all those variables are constrained to be non-negative.

The unique firm operating in the economy behaves in a competitive fashion. At every period, it chooses $l\left(s^{t}\right)$ to maximize its period profit $p\left(s^{t}\right) \theta_{t} l\left(s^{t}\right)-w\left(s^{t}\right) l\left(s^{t}\right)$.

\section{COMPETITIVE EQUILIBRIUM}

The government cannot target domestic debt, money supply, tax rate, nominal interest rate, nominal wage, and price level. Without loss of generality, we assume that the government targets the last four variables. This convention leads to simpler notation.

A history contingent date $t$ policy $\left(\tau\left(s^{t}\right), p\left(s^{t}\right), w\left(s^{t}\right), q\left(s^{t}\right)\right)$ is denoted by $\varphi\left(s^{t}\right)$. A policy is an object $\varphi=\left\{\left[\varphi\left(s^{t}\right)\right]_{s^{t} \in S^{t}}\right\}_{t=0}^{\infty}$. Date $t$ history contingent allocations $\left(c_{1}\left(s^{t}\right), c_{2}\left(s^{t}\right), l\left(s^{t}\right)\right)$ and asset holdings $\left(M\left(s^{t}\right), B\left(s^{t}\right)\right)$ are denoted, respectively, by $\chi\left(s^{t}\right)$ and $\zeta\left(s^{t}\right)$. Additionally, $\chi=\left\{\left[\chi\left(s^{t}\right)\right]_{s^{t} \in S^{t}}\right\}_{t=0}^{\infty}$ and $\zeta=\left\{\left[\zeta\left(s^{t}\right)\right]_{s^{t} \in S^{t}}\right\}_{t=0}^{\infty}$. 
Definition 3.1. A competitive equilibrium is an object $(\varphi, \chi, \zeta)$ satisfying: (i) given $\varphi,(\chi, \zeta)$ solves the household problem; (ii) $w\left(s^{t}\right)=p\left(s^{t}\right) \theta_{t}$; and (iii) (1) and (2) hold.

The next step is to characterize a competitive equilibrium. There are several possibilities to carry out this task. We will proceed in a particular way that is convenient to the purposes of this paper, as we explain below.

One of the goals we have is to compute the optimal policy and the competitive equilibrium allocation (i.e., the Ramsey allocation) induced by that policy. It is well known that the Ramsey allocation can be characterized by a standard maximization problem, provided that the competitive equilibrium is characterized just in terms of allocations. This leads to our characterization choice, which we provide next.

Let $u\left(s^{t}\right), u_{1}\left(s^{t}\right), u_{2}\left(s^{t}\right)$, and $u_{3}\left(s^{t}\right)$ denote, respectively, the value of $u$ and its partial derivatives $\partial u / \partial c_{1}, \partial u / \partial c_{2}$, and $\partial u / \partial(L-l)$ evaluated at the point $\left(c_{1}\left(s^{t}\right), c_{2}\left(s^{t}\right), L-l\left(s^{t}\right)\right)$. We denote the sum $u_{1}\left(s^{t}\right) c_{1}\left(s^{t}\right)+u_{2}\left(s^{t}\right) c_{2}\left(s^{t}\right)-u_{3}\left(s^{t}\right) l\left(s^{t}\right)$ by $W\left(s^{t}\right)$.

It is a well known fact that in Ramsey policies the government uses distorting taxation only after using all available lump-sum revenues. This implies that the date zero cash-in-advance constraint will hold as equality. Otherwise, the money holdings left over would consist of wealth not taxed away through inflation in a lump-sum fashion. So, in what follows, we assume without loss of generality that $p\left(s^{0}\right) c_{1}\left(s^{0}\right)=\bar{M}$.

The constraint

$$
\sum_{t=0}^{\infty} \sum_{s^{t} \in S^{t}} \beta^{t} \mu\left(s^{t}\right) W\left(s^{t}\right)=u_{1}\left(s^{0}\right) c_{1}\left(s^{0}\right)
$$

consolidates the family of period budget constraints in (5), while

$$
u_{2}\left(s^{t}\right) \leq u_{1}\left(s^{t}\right)
$$

ensures that $q\left(s^{t}\right) \leq 1$, that is, money is dominated in rate of return. ${ }^{2}$

As Chari et al. (1995) pointed out, if an allocation $\chi$ satisfies (1), (7) and (8), then it can be decentralized as a competitive equilibrium. Formally, the following proposition can be established:

Proposition 3.2. Suppose that $\bar{M}>0$. If an object $(\varphi, \chi, \zeta)$ satisfies (1), (7) and (8), then $(\varphi, \chi, \zeta)$ is a competitive equilibrium. Conversely, if an array $\chi$ satisfies (1), (7) and (8), then there exists a policy $\varphi$ and a portfolio $\zeta$ such that $(\varphi, \chi, \zeta)$ is a competitive equilibrium.

This above result is standard in the literature on optimal policy. For this reason we do not present a proof here. We refer the interested reader to Chari and Kehoe (1999).

\section{PARAMETERIZATION}

We borrow most of the parameter values from Chari et al. (1995). For the sake of completeness, we outline their procedure in this section.

Chari et al. (1995) calibrated the Markov process for government consumption so that it matched the mean value of the ratio $g / y$ and the variance and serial correlation of the detrended log of government consumption. They calibrated the Markov chain for the technology shocks to replicate the variance and serial correlation of its actual US counterpart.

With respect to preferences, the discount factor $\beta$, the share factor $\gamma$ and the endowment $L$ are the same as in Christiano and Eichenbaum (1992). A regression of the ratio of real balances to aggregate

\footnotetext{
${ }^{2}$ We obtained both (7) and (8) from the households' first order conditions. We list those conditions in the Appendix.
} 
consumption against nominal interest rate determined the values of $\nu$ and $\rho$. Concerning the risk aversion parameter, we will run the policy exercises in Section 5 for $\sigma=1$, so that the period utility is logarithmic, and $\sigma=1.5$, which is the value used in the seminal paper of Kydland and Prescott (1982).

The table that follows contains the selected parameter values.

Table 1: Parameter Values

\begin{tabular}{c|c}
\hline government consumption & $\left(g_{L}, g_{H}, \mu_{g}\right)=(350,402,0.95)$ \\
\hline technology & $\left(\theta_{L}, \theta_{H}, \mu_{\theta}\right)=(0.974,1.027,0.91)$ \\
\hline preferences & $(\beta, \gamma, \rho, \nu, L)=(0.97,0.8,0.83,0.57,5475)$ \\
\hline
\end{tabular}

\section{POLICY ANALYSIS}

In this section we compare the implications of distinct macroeconomic policies for the artificial economy studied in this paper. We carry out the traditional real business cycle analysis of first and second moments and the spectral analysis proposed by Söderlind (1993). We also provide welfare comparison of the alternative policies.

We consider three alternative policies: the Ramsey policy, a second one that specifies constant rates for tax on labor income and money supply growth, and one that ensures that all output oscillations are totally smoothed out. We now further elaborate on this point.

The Ramsey equilibrium corresponds to the competitive equilibrium that yields the highest possible expected lifetime utility. Given the result established in Proposition 3.2, to compute the Ramsey allocation, it suffices to solve the problem of maximizing (4) subject to (1), (7) and (8). The solution of that problem has no endogenous state variable. Thus, it turns out that, for $t \geq 1$ and each $s^{t}$, the optimal choice of $\left(c_{1}\left(s^{t}\right), c_{2}\left(s^{t}\right), l\left(s^{t}\right)\right)$ depends only on the current state $\left(\theta_{t}, g_{t}\right)$. Since $\left(\theta_{t}, g_{t}\right)$ belongs to a four element set, the Ramsey allocation is characterized by four vectors $\left(c_{1}, c_{2}, l\right)$, one for each possible realization of $\left(\theta_{t}, g_{t}\right)$, plus an additional vector corresponding to the date zero allocation. This allowed us to use the well-known Newton method for non-linear systems to compute the optimal allocations. ${ }^{3}$

One of the goals of this paper is to evaluate the welfare implications of a macroeconomic policy that stabilizes output. Of course, such a policy must yield less utility than the Ramsey one. What is not clear is whether there exists some simple policy rule that yields higher utility than the one that fully smoothes output out. It turns out that such a policy exists. Consider a very simple policy rule, under which money supply grows at a constant rate of $5.935 \%$ per year and the tax rate on labor income is constant at some level that balances the government's lifetime budget constraint. We call the competitive equilibrium induced by that simply policy rule the baseline equilibrium.

Note that Proposition 3.2 establishes that any competitive equilibrium must satisfy (1), (7) and (8). Thus, the baseline equilibrium must satisfy them too. Additionally, the constraint that money supply grows at the rate $5.935 \%$ requires

$$
\frac{\beta}{\mu\left(s^{t}\right) u_{2}\left(s^{t}\right) c_{1}\left(s^{t}\right)} \sum_{s \in S} \mu\left(s^{t}, s\right) u_{1}\left(s^{t}, s\right) c_{1}\left(s^{t}, s\right)=1.05935
$$

for every $s^{t}$, while the fact that the tax rate on labor income is constant requires the factor

$$
\theta_{t} \frac{u_{3}\left(s^{t}\right)}{u_{2}\left(s^{t}\right)}
$$

\footnotetext{
${ }^{3}$ All equilibria discussed in this paper are stationary, in the sense that the date $t$ allocations depend only on $\left(\theta_{t}, g_{t}\right)$. This feature allowed us to use Newton's method to compute all equilibria.
} 
to be constant. We obtained both (9) and (10) from household's first-order conditions. ${ }^{4}$ One can think of our baseline equilibrium as the competitive equilibrium induced by stable and credible macroeconomic policies that the government announces at date zero and follows from then on.

The tax smoothing equilibrium is the competitive equilibrium induced by macroeconomic policies that use the tax rate on labor income as an instrument to keep the output constant. As the baseline one, the tax smoothing equilibrium must respect (1), (7) and (8). Additionally, we require it to satisfy (9), because we want the only deviation from the baseline policy to be on the fiscal side. Thus, the only difference in the characterization of the tax smoothing equilibrium from the baseline one is that condition (10) is replaced by

$$
\theta_{t} l\left(s^{t}\right)=\theta_{0} l\left(s^{0}\right)
$$

for all possible histories $s^{t}$. One can see the tax smoothing equilibrium as the competitive equilibrium induced by an active output stabilization policy.

We carry out the forthcoming analysis for two different values for the preference parameter $\sigma$. We provide a detailed analysis for the case in which $\sigma=1$. Since the results are roughly the same, we only briefly discuss the results for the case in which $\sigma=1.5$.

\subsection{First and second moment comparisons}

We report next the first and second moments of selected variables of the Ramsey equilibrium. As usual, $\pi$ denotes the inflation rate. ${ }^{5}$

Table 2: First and Second Moments - Ramsey Equilibrium $(\sigma=1)$

\begin{tabular}{c|c|c|c|c|c|c}
\hline variable & $y$ & $\frac{M}{p}$ & $\left(c_{1}+c_{2}\right)$ & $l$ & $\tau(\%)$ & $\pi(\%)$ \\
\hline mean & 7.0027 & 4.7548 & 6.5872 & 7.0013 & 33.7618 & -3.0143 \\
\hline std.dev. & 0.0246 & 0.0283 & 0.0283 & 0.0188 & 0.1060 & 1.7448 \\
\hline
\end{tabular}

We report in Table 3 the sample first and second moments of the baseline equilibrium.

Table 3: First and Second Moments - Baseline Equilibrium $(\sigma=1)$

\begin{tabular}{c|c|c|c|c|c|c}
\hline variable & $y$ & $\frac{M}{p}$ & $\left(c_{1}+c_{2}\right)$ & $l$ & $\tau(\%)$ & $\pi(\%)$ \\
\hline mean & 7.0004 & 4.4594 & 6.4565 & 6.9991 & 33.5546 & 2.7496 \\
\hline std.dev. & 0.0249 & 0.0275 & 0.0275 & 0.0198 & 0 & 1.7038 \\
\hline
\end{tabular}

Mean output is slightly higher in the Ramsey than in the baseline equilibrium. The opposite happens with its standard deviation. Ramsey real balances and private consumption are higher and less volatile than in the baseline equilibrium. Ramsey labor is slightly higher on average and less volatile. Inflation is higher and less volatile in the baseline equilibrium.

We report next the simulated first and second moments of the tax smoothing equilibrium.

Table 4: First and Second Moments - Tax Smoothing Equilibrium $(\sigma=1)$

\begin{tabular}{c|c|c|c|c|c|c}
\hline variable & $y$ & $\frac{M}{p}$ & $\left(c_{1}+c_{2}\right)$ & $l$ & $\tau(\%)$ & $\pi(\%)$ \\
\hline mean & 6.9990 & 4.4565 & 6.5809 & 6.9977 & 33.6902 & 2.7508 \\
\hline std.dev. & 0 & 0.0323 & 0.0323 & 0.0252 & 2.9285 & 1.5708 \\
\hline
\end{tabular}

\footnotetext{
${ }^{4}$ We list all first-order conditions in the Appendix.

${ }^{5}$ All reported statistics are based on 500 sample realizations, each of them of size 100 , of $\left(\theta_{t}, g_{t}\right)$. We also assume that $s_{0}=$ $\left(\theta_{H}, g_{L}\right)$.
} 
Compared to both Ramsey and baseline ones, the tax smoothing equilibrium has a lower average value for output and hours worked. Except for output and inflation, all variables are more volatile in the tax smoothing equilibrium than in the baseline.

We observe that the elimination of output volatility has two types of implications. First, it comes at the expense of a lower output on average. Second, the volatility of other real variables has to rise. Moreover, we also carried out the first and second moment analysis for $\sigma=1.5$. The results are virtually the same. Consequently, we do not report them for the sake of brevity.

\subsection{Frequency domain analysis}

The aim of this subsection is to compare cyclical properties of the three policy regimes. We carry out an alternative assessment of the computed equilibria by performing frequency domain analysis. However, none of the computed equilibria are designed to match statistical properties of macroeconomic variables. The model economy presented in this paper does not have enough structure to capture all relevant cyclical properties. For instance, it has no physical capital and the only existing friction is the cash-in-advance constraint. Consequently, we do not attempt a comparison with data sets from any country.

Despite the aforementioned limitations, an assessment of the policy experiments is a valuable task for three reasons. First, a comparison between the three equilibria can reveal in which dimensions they perform differently, which can suggest the incorporation of additional features in future extensions of the model. Second, this assessment can work as a robustness check in the sense that it is able to gauge how the properties of a very simple artificial economy can change according to alternative policies. Third, the analysis of the time series properties of the computed equilibria provides us with counterfactual macroeconomic scenarios. In other words, since policy makers are probably not strictly following any of the policy experiments studied here, the cyclical properties generated by the computed equilibria may be thought of as the properties one would expect to find in the data if policy makers were behaving precisely as described by the particular equilibrium.

In subsection 5.1 we carried out the traditional real business cycle analysis of first and second moment statistics across simulations. In the present subsection we follow Söderlind (1993) and perform a frequency domain analysis of the time series generated by each equilibrium. The approach to implement this exercise goes as follows. We simulate a set of 500 realizations of macroeconomic variables for each particular equilibrium studied. The time series generated by each policy regime comprise 100 observations for each macroeconomic variable. We then compute the median of some statistics in the frequency domain, which we describe below, across these 500 replications of length 100 . Finally, we construct $95 \%$ confidence bands.

We focus on three macroeconomic series: GDP, aggregate consumption and inflation. We compute spectral density functions for each time series in order to analyze volatility across different frequency bands since the area under the spectral density is the variance associated with a particular band of frequency, which represents cycles of a particular periodicity. To study the comovement of consumption and inflation with GDP, we evaluate the coherence, which is a frequency domain analogue of the $R^{2}$ of basic regression analysis. It is worth noting that since, by design, GDP is kept constant in the tax smoothing equilibrium, there is no point in computing comovement measures and spectral density functions for GDP in that particular equilibrium.

The results presented in Figures 1 to 5 are based on the parameterization in which $\sigma=1$. The solid line represents the median of a particular statistics across simulations and dashed lines delimited the $95 \%$ confidence region. Figures 1 to 3 show spectral densities for GDP, aggregate consumption and inflation. In these figures, each line corresponds to a particular policy experiment (Ramsey, baseline and tax smoothing). Since GDP is constant in the tax smoothing equilibrium, there is no line corresponding to this equilibrium in Figure 1. 
We now discuss the results in Figures 1 to 3. Concerning GDP, the Ramsey and the baseline equilibrium generate basically the same spectral density. Since the model has limited propagation mechanisms, technology shocks, which follow the same stochastic process in both equilibria, drive GDP. Therefore, spectral densities in these equilibria tend to coincide. Concerning consumption, in all equilibria, low frequencies concentrate a great percentage of the volatility and spectral shapes are very similar across equilibria. For inflation, all equilibria display almost flat spectral densities.

Figure 1: Spectral Density - GDP
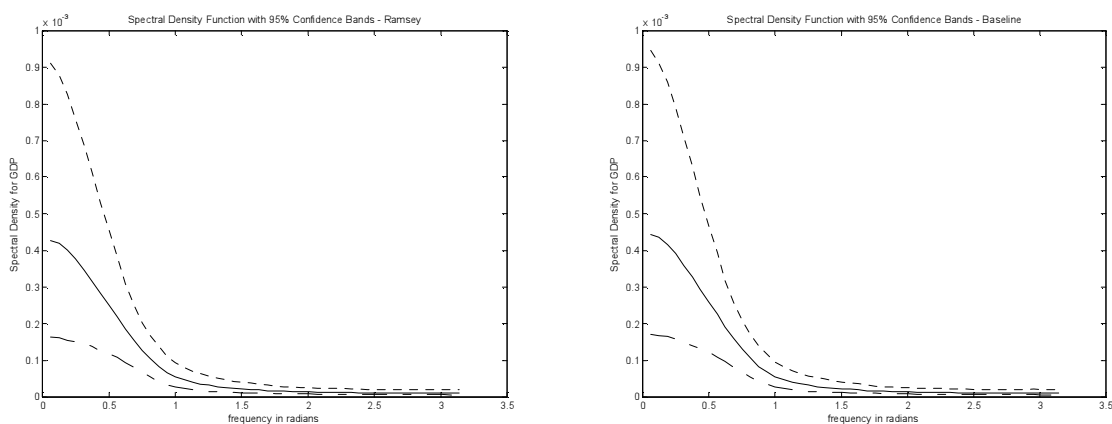

Figure 2: Spectral Density - Consumption
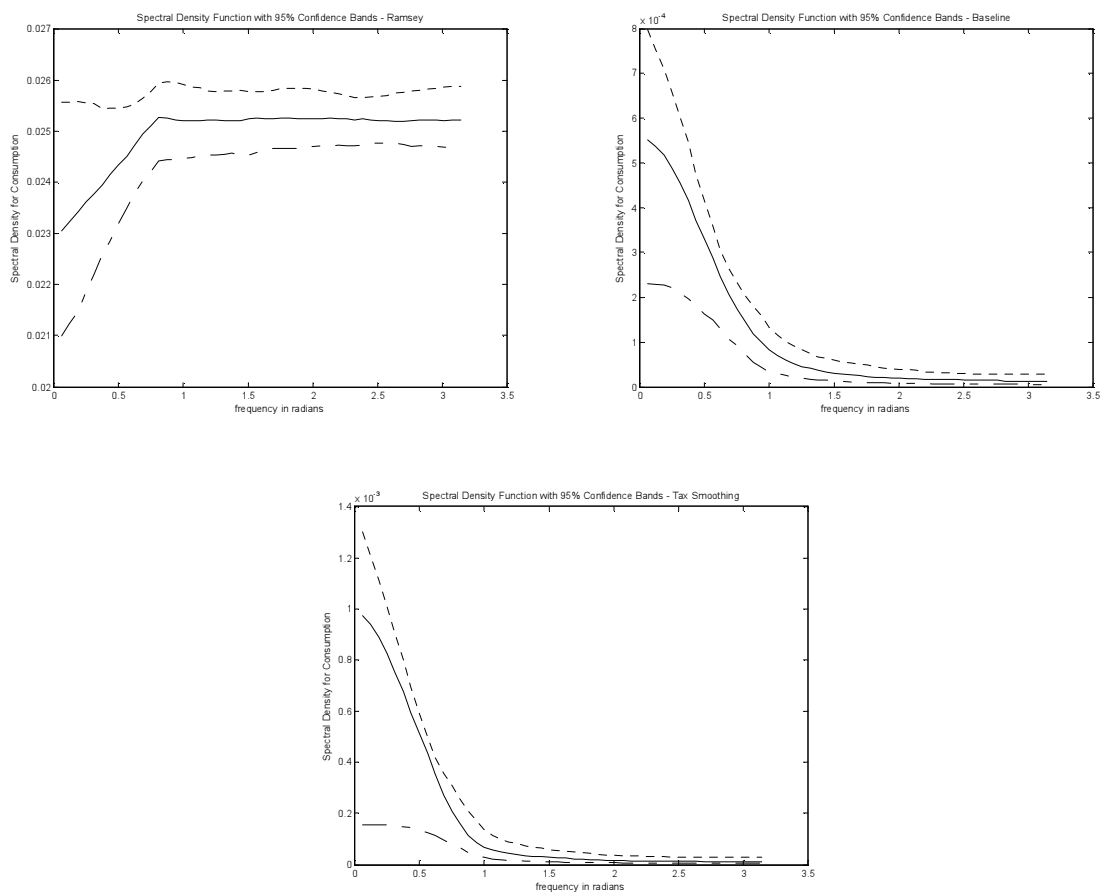
Figure 3: Spectral Density - Inflation
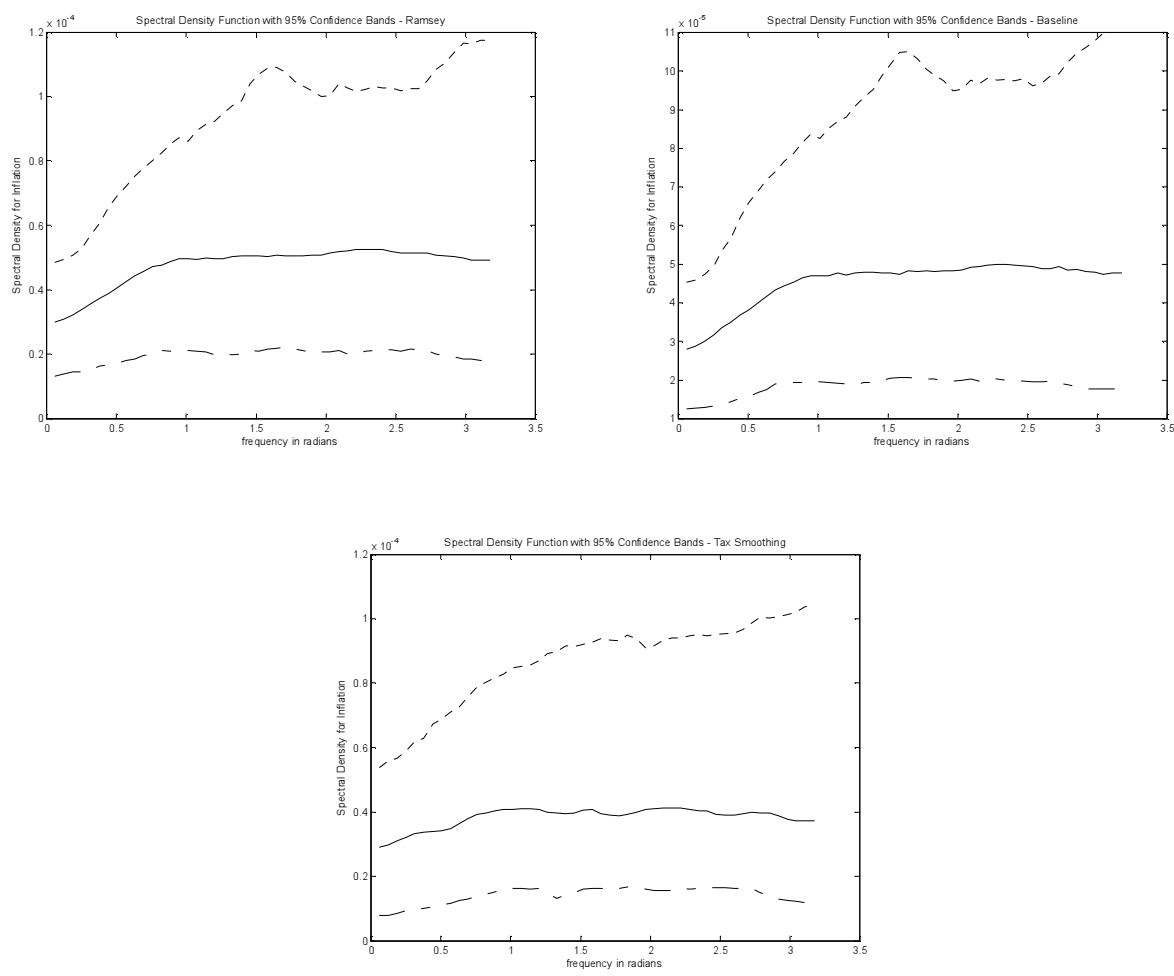

Figures 4 and 5 display measures of comovement with GDP for aggregate consumption and inflation. Each figure displays coherence measures. The first line corresponds to the Ramsey equilibrium and the second to the baseline equilibrium. Next, we present the findings in Figures 4 and 5 . In the equilibria we considered in these figures, consumption comoves weakly with GDP, especially in the low frequency range, with median coherence values of less than 0.5 . Indeed, consumption in the Ramsey equilibrium is almost independent of GDP. The two policy experiments generate inflation realizations with substantial comovement in intermediate and high frequency ranges.

In short, the low coherence between consumption and GDP distinguishes the Ramsey equilibrium from the baseline equilibrium. Concerning the tax smoothing experiment, spectral shapes and the comovement between consumption and GDP do not substantially change when compared with the baseline case. Since different equilibria imply different volatility patterns, the scale of the spectral density functions changes to some extent according to the policy experiment, but the equilibrium effect on spectral shapes is not significant. 
Figure 4: Coherence with GDP - Consumption
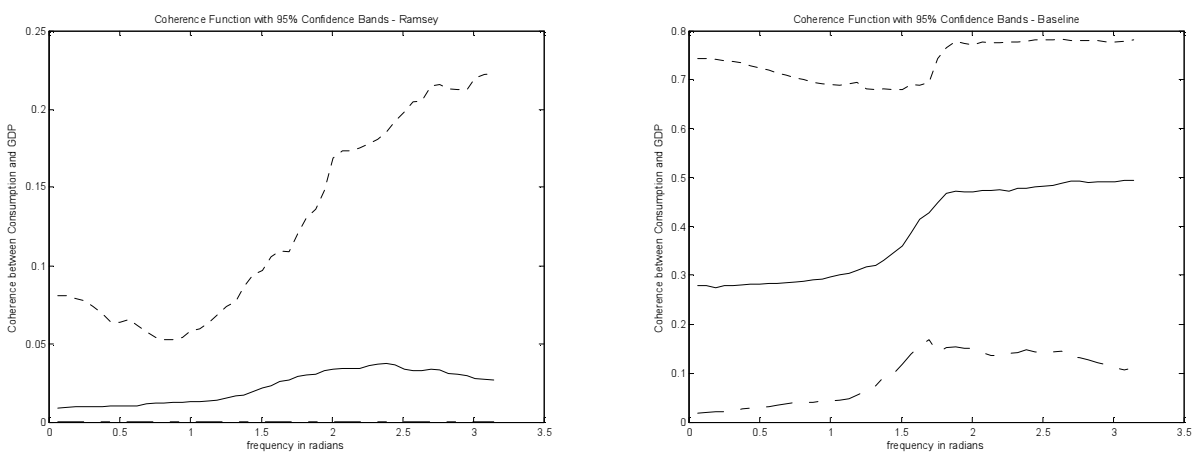

Figure 5: Coherence with GDP - Inflation
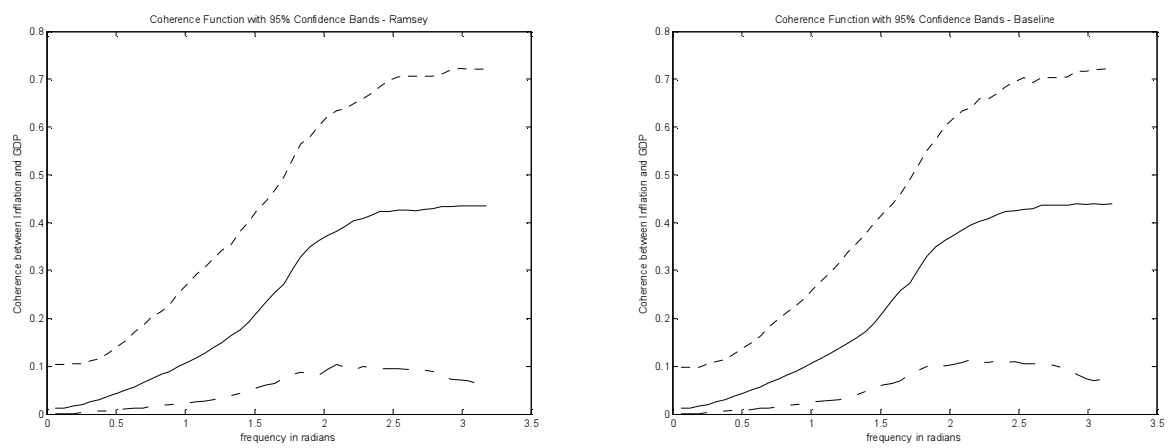


\subsection{Welfare implications}

Let $U^{r}, U^{b}$ and $U^{\tau}$ denote, respectively, the expected lifetime utility under the Ramsey, baseline and tax smoothing policies. We found out that $U^{r}>U^{b}>U^{\tau}$ for both $\sigma=1$ and $\sigma=1.5$. This finding suggests that, contrary to the conventional wisdom, output variability and business cycles are not necessarily costly.

The definition of Ramsey equilibrium implies the inequalities $U^{r}>U^{b}$ and $U^{r}>U^{\tau}$. It remains to understand why $U^{\tau}$ is smaller than $U^{b}$.

A key variable to understand the above utility ranking is the tax rate on labor income. In the baseline equilibrium, $\tau$ is constant and approximately equal to 33.55\%. The Ramsey tax on labor income is roughly constant, since $33.63 \% \simeq \tau\left(\theta_{H}, g_{L}\right)<\tau\left(\theta_{L}, g_{L}\right)<\tau\left(\theta_{H}, g_{H}\right)<\tau\left(\theta_{L}, g_{H}\right) \simeq 33,93 \%$. However, the same does not apply in the tax smoothing equilibrium. The tax rate ranges from $38.29 \%$ at state $\left(\theta_{H}, g_{H}\right)$ to $29.12 \%$ at state $\left(\theta_{L}, g_{L}\right)$. The requirement of keeping the output constant drives the tax rate on labor away from its optimal path. This does not happen in the baseline equilibrium.

We also measured the benefits of shifting from the baseline to the Ramsey policies. Following the procedure that is standard in the literature on the costs of business cycle fluctuations, we measured the benefit as the uniform (i.e., over all $t$ and all $s^{t}$ ) percent increase in the baseline $c_{1}$ and $c_{2}$ that would make people indifferent between the baseline and the Ramsey policies. Our findings are reported in Table 5.

Table 5: Welfare Gains and Losses

\begin{tabular}{l|c|c}
\hline policy experiment & $\sigma=1$ & $\sigma=1.5$ \\
\hline from baseline to Ramsey & $0.1716 \%$ & $0.1713 \%$ \\
\hline from baseline to tax smoothing & $-0.0930 \%$ & $-0.0928 \%$ \\
\hline
\end{tabular}

As usual in the related literature, we obtained small figures. However, in contrast to most authors, we found that policies aimed at smoothing out business cycles do not necessarily improve welfare.

\section{CONCLUDING REMARKS}

We carried out a quantitative comparison of three macroeconomic policies in a monetary model with cash-credit goods and distorting taxation on labor income. The policies are:

(i) the optimal (in the Ramsey sense) policy;

(ii) a policy that leads to an equilibrium in which output is constant over time; and

(iii) a simple policy that keeps the rates of tax on labor income and monetary growth constant over time.

Not surprisingly, the active policy that fully smoothes out the business cycle is dominated, in a welfare sense, by the Ramsey policy. What we see as a surprise is the finding that the active policy is worse than the simple policy of constant rates for taxes and monetary growth. Hopefully, future research will provide further insights into this important issue.

\section{BIBLIOGRAPHY}

Chari, V. V., Christiano, L., \& Kehoe, P. (1994). Optimal fiscal policy in a business cycle model. Journal of Political Economy, 102:617-652.

Chari, V. V., Christiano, L., \& Kehoe, P. (1995). Policy analysis in business cycle models. In Cooley, T., editor, Frontier of Business Cycle Research, pages 357-391. Princeton University Press, New Jersey. 
Chari, V. V. \& Kehoe, P. (1999). Optimal fiscal and monetary policy. In Taylor, B. \& Woodford, M., editors, Handbook of Macroeconomics, volume 1C, pages 1671-1745. North-Holland, Amsterdam.

Christiano, L. \& Eichenbaum, M. (1992). Current real business cycle theory and aggregate labor market fluctuations. American Economic Review, 82:430-450.

Galí, J., Gertler, M., \& López-Salido, J. D. (2007). Markups, gaps, and the welfare costs of business fluctuations. Review of Economics and Statistics, 89:44-59.

Guillén, O. T. C., Issler, J. V., \& Franco-Neto, A. A. M. (2014). On the welfare costs of business-cycle fluctuations and economic-growth variation in the 20th century and beyond. Journal of Economic Dynamics and Control, 39:62-78.

Keynes, J. M. (1936). The General Theory of Employment, Interest and Money. Harcourt \& Brace, New York.

Krusell, P. \& Smith, A. J. (1999). On the welfare effects of eliminating business cycles. Review of Economic Dynamics, 2:245-272.

Kydland, F. \& Prescott, E. (1982). Time to build and aggregate fluctuations. Econometrica, 50:1345-1370.

Lucas, R. (1987). Models of Business Cycles. Basil Blackwell, New York.

Lucas, R. (2003). Macroeconomic priorities. American Economic Review, 93:1-14.

Nicolini, J. (1998). More on the time consistency of the monetary policy. Journal of Monetary Economics, 41:333-350.

Otrok, C. (2001). On measuring the welfare cost of business cycles. Journal of Monetary Economics, 47:61-92.

Söderlind, P. (1993). Cyclical properties of a real business cycle model. Journal of Applied Econometrics, 9:S113-S122. 


\section{A. APPENDIX}

If $\bar{M}$ is positive, the first-order necessary and sufficient conditions for a typical household are

$$
\begin{gathered}
\beta^{t} \mu\left(s^{t}\right) u_{1}\left(s^{t}\right)=\left[\lambda\left(s^{t}\right)+\xi\left(s^{t}\right)\right] p\left(s^{t}\right) ; \\
\beta^{t} \mu\left(s^{t}\right) u_{2}\left(s^{t}\right)=\lambda\left(s^{t}\right) p\left(s^{t}\right) ; \\
\beta^{t} \mu\left(s^{t}\right) u_{3}\left(s^{t}\right)=\lambda\left(s^{t}\right)\left[1-\tau\left(s^{t}\right)\right] w\left(s^{t}\right) ; \\
\lambda\left(s^{t}\right)=\sum_{s_{t+1} \in S}\left[\lambda\left(s^{t}, s_{t+1}\right)+\xi\left(s^{t}, s_{t+1}\right)\right] ; \\
\lambda\left(s^{t}\right) q\left(s^{t}\right)=\sum_{s_{t+1} \in S} \lambda\left(s^{t}, s_{t+1}\right) ; \\
M\left(s^{t-1}\right) \geq p\left(s^{t}\right) c_{1}\left(s^{t}\right) \& \xi\left(s^{t}\right)\left[M\left(s^{t-1}\right)-p\left(s^{t}\right) c_{1}\left(s^{t}\right)\right]=0 ; \\
p\left(s^{t}\right)\left[c_{1}\left(s^{t}\right)+c_{2}\left(s^{t}\right)\right]+q\left(s^{t}\right) B\left(s^{t}\right)+M\left(s^{t}\right)= \\
{\left[1-\tau\left(s^{t}\right)\right] w\left(s^{t}\right) l\left(s^{t}\right)+B\left(s^{t-1}\right)+M\left(s^{t-1}\right) ;} \\
\lim _{t \rightarrow \infty} \sum_{s^{t} \in S^{t}} \lambda\left(s^{t}\right) M\left(s^{t}\right)=\lim _{t \rightarrow \infty} \sum_{s^{t} \in S^{t}} \lambda\left(s^{t}\right) q\left(s^{t}\right) B\left(s^{t}\right)=0 ; \\
c_{1}\left(s^{t}\right), c_{2}\left(s^{t}\right), l\left(s^{t}\right), M\left(s^{t}\right), \lambda\left(s^{t}\right), \xi\left(s^{t}\right) \geq 0, l\left(s^{t}\right) \leq L ;
\end{gathered}
$$

where $\lambda\left(s^{t}\right)$ and $\xi\left(s^{t}\right)$ are Lagrange multipliers for, respectively, budget and cash-in-advance constraints. 